\title{
Lewis Acid-Promoted Radical Carbon-Carbon Bond Forming Reactions with $N$-Ethylpiperidine Hypophosphite
}

\author{
Dae Hyan Cho and Doo OK Jang* \\ Department of Chemistry, Yonsei Cmiversity, Honju 220-710, Korea \\ Received October 28. 2002
}

Key Words : Lewis acid. Radical. Addition

Construction of carbon-carbon bonds is one of the most important tasks in organic synthesis. and the well-developed radical reactions have become important synthetic tools for forming carbon-carbon bonds of biologically important molecules. ' In the process. organotin hydrides have played a major role. Although organotin hydrides give high yields. they have several drawbacks. Their toxicity prevents them from being used on a practical scale. and it is difficult to elininate toxic by-products from the desired products. Therefore. organotin hydrides are not acceptable in an industrial process of manufacturing drugs and medicines. Consequently, various altematives to organotin hydrides have been reported. ${ }^{\hat{}}$ Among them, hypophosphorous acid and its salts have shown to be suitable alternatives to organotin hydrides in radical reactions. ${ }^{3}$ Hypophosphorous acid and its salts have advantages over organotin hydrides in cost-effectiveness. non-toxicity and easy work-up process.

Electron-deficient alkenes are generally employed in radical carbon-carbon bond forming reactions because of the nucleoplilic character of alkyl radicals which are the most frequently used radical donors in organic synthesis. ${ }^{\text {li, } 4}$ However. it is not easy to accomplish the radical carbon-carbon bond forming reactions with $\beta$-substituted alkenes even though $\beta$-substituted alkenes have an electron-withdrawing group. Therefore. a general method for the radical carboncarbon bond forming reactions with $\beta$-substituted alkenes is highly appreciated.

Our recent studies on the radical addition reactions with $N$-ethylpiperidine hypophosphite (EPHP) showed that $\beta$ substituted alkenes are hardly radical acceptors. ${ }^{3}$ Recently.

Table 1. Effect of Lewis acids on radical addition reaction to methyl crotonate ( 10 equiv) in dioxane

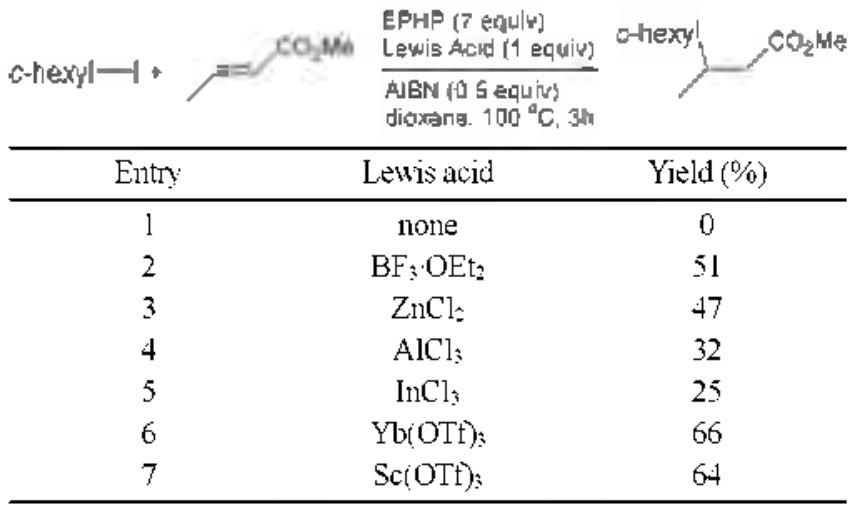

Lewis acids are frequently employed in radical reactions, especially for stereoselective radical reactions. ${ }^{6}$ We anticipated that use of Lewis acids in radical addition reactions

Table 2. Reaction of cyclohexyl iodide and various $\beta$-substituted alkenes (10 equiv) with EPHP (7 equiv) in the presence of $\mathrm{Yb}(\mathrm{OTf})$ in diosane

Entry


with EPHP would inprove the reactivity of the radical acceptor by increasing the electron-withdrawing nature of an olefinic linkage via complexation of a Lewis acid. Herein. we report on Lewis acid-promoted radical carbon-carbon bond forming reactions of $\beta$-substituted alkenes with EPHP.

The first system chosen for this study was the reaction of cyclohexyl iodide and methyl crotonate with a series of Lewis acids to determine which were most effective at promoting addition reactions (Table 1 ). In the absence of a Lewis acid. no addition product was detected. Lewis acids in lantanide family. $\mathrm{Yb}(\mathrm{OTf})_{3}$ and $\mathrm{Sc}(\mathrm{OTf})_{3}$ proved to be highly effective promoters for the radical addition reactions of $\dot{\beta}$ substituted alkenes with EPHP, while common Lewis acids such as $\mathrm{BF}_{3} \cdot \mathrm{OEt}_{3}, \mathrm{ZnCl}_{2}, \mathrm{AlCl}_{3}$ and $\mathrm{InCl}_{3}$ enhanced the $y$ ields of the addition product moderately.

$\mathrm{Yb}(\mathrm{OTf})_{3}$ is the choice of Lewis acid for the addition reactions. The reactivity of various $\beta$-substituted alkenes was surveyed under reaction conditions. and the results are sunumarized in Table 2 . The reaction of 2-cyclopentenone under the standard reaction conditions produced an $86 \%$ yield of the addition product (entry 1). A blank experiment was carried out without using $\mathrm{Yb}(\mathrm{OTf})_{3}$, which gave a low $y$ ield of the addition product (entry 2). Although the reaction proceeded smoothly at room temperature using $\mathrm{Et}_{3} \mathrm{~B}$ as initiator, 3-ethylcyclopentanone. ethylated by-product was also produced along with the desired addition product (entry 3). Cyclic enones afforded high yields of the addition products (entries 4 and 5). However. $\beta$-substituted cyclic enones remained intact (entry 6). Unsaturated lactone. acyclic ketone and nitrile gave the addition products in moderate yields under reaction conditions (entries 7-9).

In conclusion. we have shown that Lewis acids promote EPHP-mediated radical addition reactions. Our method may be used as a process of forming carbon-carbon bonds with $\beta$ substituted alkenes in synthetic chemistry

Typical procedure: A solution of cyclohexyl iodide $(0.043$ $\mathrm{mL} .0 .333 \mathrm{mmol}), 2$-cyclopentenone $(0.28 \mathrm{~mL} .3 .33 \mathrm{nmol})$. $\mathrm{Yb}(\mathrm{OTf})_{3}(207 \mathrm{mg} .0 .333 \mathrm{mmol})$ and EPHP $(2.21 \mathrm{~mL} .2 .33$ mmol. $1.05 \mathrm{M}$ solution in dioxane) in dry dioxane $(3 \mathrm{~mL})$ under argon was treated with AIBN ( $28 \mathrm{mg} .0 .167 \mathrm{mmol}$ ) twice (30 min interval) during reflux. The reaction was followed by TLC. When the reaction was completed the reaction mixture was washed with saturated $\mathrm{NH}_{4} \mathrm{Cl}$ and brine. The organic layer was dried over anhydrous $\mathrm{MgSO}_{4}$ After filtration. the solvent was removed in vacuum and the residue was separated by flash column chromatography on silica gel (eluent : hexanes/EtOAc, $10: 1$ ) to afford 3-cyclohexylcyclopentanone ( $48 \mathrm{mg} .86 \%$ ).

Acknowledgment. This work was supported by Korea Research Foundation Grant (KRF-2001-041-D00144).

\section{References}

1. (a) Giese. B. Radicals in Organic Synthesis: Fomation of CarbonCarbon Bonds: Pergamon Press: Onford. 1986. (b) Curran. D. P. Symthesis 1988. 417 . (c) Curran. D. P. Smthesis 1988. 489. (d) Curran. D. P. In Comprehensine Organic Symthesis: Trost. B. M.: Fleming. I.. Eds.: Pergamon: Oxford, 1991: Vol. 4. p 715. (e) Motherwell, W. Crich. D. Fine Radical Chain Reactions in Organic Symhesis: Academic Press: London. 1992.

2. For recent reviews: (a) Baguley. P. A.: Waltonl. J. C. Angew: Chent. Int. Ed. Engt 1998. 37. 3072. (b) Studer. A.: Amrein. S. Simhesis 2002. 835 .

3. (a) Barton, D. H. R. Jang, D. O.: Jaszberenyi, J. C. Tetrohedhon Lett. 1992. 33. 5709. (b) Barton. D. H. R.: Jang. D. O: Jaszberenyi. J. C. J. Org. Chem. 1993. 58.6838. (c) MoCague, R. Pritchard. R. G.: Stoodley. R. T.: Williamson. D. S. J. Chem. Soc. Chent Commm. 1998. 2691. (d) Tokuyama. H.: Yamashita. T. Reding. M. T.: Kaburagi. Y: Fukuyama. T. J. Am. Chem. Soc. 1999. 121, 3791. (e) Graham. S. R.; Murphy, J. A.: Coates. D. Tetrahedron Lett. 1999. 40. 2415. (f) Graham. S. R.: Murphy. J. A.; Kennedy. A. R. J. Chem. Soc. Porhin Trans. 1 1999. 3071 . (g) Jang. D. Q.: Song. S. H. Tetahedron Lett. 2000. H1. 247. (h) Martin. C. G.: Murphy. J. A.: Smith. C. R. Tetrahedron Lett. 2000. H. 1833. (i) Takamatsu. S.: Katayama. S.: Hirose. N.: Naito. M.: Izawa, K. Tetrahedron Lett. 2001. +2,7605. (j) Jang, D. O.: Cho. D. H: Chung. C.-M. Synlett 2001. 1923. (k) Jang. D. O. Tetrahedron Lett. 1996, 37. 5367. (1) Kita, Y.: Nambu. H.: Ramesh, N. G.: Anikumar. G.: Matsugi. M. Org. Lett. 2001. 3. 1157. (m) Jang. D. O.: Cho. D. H. Snlen 2002. 631. (11) Graham. A. E.: Thomas. A. V: Yantg. R. J. Org Chem. 2000. 65. 2583. (o) Yorimitsu, H; Shinokubo. H; Oshima, K. Chent. Lett. 2000. 104. (p) Yorimitsu. H.: Shinokubo, H.: Oshima, K. Bull. Chem. Soc. Jpn $2001,7 f, 225$.

4. Smadja. W. Symlett 1994. 1 .

5. Urabe. H.: Yamashita. K.: Suzuki. K.: Kobayashi. K.: Sato. F. $J$ Org. Chem. 1995.60.3576.

6. For reviews: (a) Renaud. P.: Gerster. M. Angew. Chent. Int. Ed. 1998. 37, 2562. (b) Curran. D. P: Porter. N. A.: Giese, B. Stereochemisny of Radical Reactions; VCH: Weinheim, 1996. 